\title{
Das mediações aos mundos possíveis: percurso teórico metodológico de um estudo de recepção com mulheres encarceradas
}

\author{
Valquiria Michela John \\ Doutora; Universidade Federal do Paraná, Curitiba, PR, Brasil \\ vmichela@gmail.com
}

\section{Resumo}

Este artigo apresenta o itinerário teórico metodológico de uma pesquisa que articula a proposição das mediações de Jesús Martín-Barbero e como esta possibilitou compreender o cotidiano de mulheres em situação de confinamento e como este se (re)configura a partir da mediação da telenovela nesse novo ambiente de socialização. O mapa das mediações de Martín-Barbero não foi o fio condutor do estudo, que se norteia pela perspectiva dos mundos possíveis de Galindo Cáceres, entretanto, é justamente no encontro dessas duas perspectivas teórico metodológicas que se buscou compreender como a telenovela medeia o cotidiano de mulheres detentas. 0 texto busca compartilhar o caminho teórico percorrido, que embora não tenha no mapa das mediações de Martín-Barbero seu modelo metodológico, tem na proposição das mediações o elemento central para compreender a telenovela na prisão como uma instância eminente dos mundos possíveis.

\section{Palavras-chave}

Mediações. Mundos possíveis. Mulheres detentas. Telenovela. Estudo de recepção.

\section{Introdução}

Este artigo realiza um duplo movimento: primeiro, o de pensar sobre a importância da obra De los medios a las mediaciones de Jesús Martín-Barbero que, em 2017, completou 30 anos. Foi justamente do convite para a jornada em homenagem ao autor que nasceu este texto, cuja proposta é a de apresentar como a perspectiva das mediações é parte importante 
em minha trajetória como pesquisadora. ${ }^{1} 0$ segundo movimento é justamente esse: compartilhar como se deu meu itinerário de pesquisa para a realização da tese que tem como ponto de partida a proposição das mediações do autor. Aqui compartilho, portanto, a trajetória teórico metodológica que levou à realização da pesquisa que resultaria em minha tese de doutorado. Intitulada Mundos possíveis e telenovela: memórias e narrativas melodramáticas de mulheres encarceradas (JOHN, 2014), a tese foi defendida, em 2014, no Programa de Pós-Graduação em Comunicação e Informação da Universidade Federal do Rio Grande do Sul e teve a orientação da profa. Dra. Nilda Jacks.

A partir das proposições da Metodologia de los mundos posibles de Luis Jesús Galindo Cáceres (1997) e das mediações de Jesús Martín-Barbero (2003) busquei “[...] compreender como a telenovela medeia o cotidiano de mulheres detentas, como articula outros mundos que vão além dos limites impostos pelas grades e como esses mundos se relacionam com as temporalidades da prisão, bem como de suas memórias." (JOHN, 2014, p. 10)². A principal técnica adotada foi a história de vida em consonância com a proposição de Galindo Cáceres. A escolha da telenovela como objeto de estudo deve-se à observação do trabalho de campo realizado na pesquisa de dissertação (JOHN, 2004), também no ambiente prisional, mas que não teve como sujeitos participantes as mulheres. 0 estudo tinha deixado latente a necessidade de compreender a relação que elas estabelecem com essa narrativa durante o cumprimento de sua pena. Neste sentido, o objetivo da pesquisa realizada durante o doutorado foi o de "[...] compreender como a telenovela participa do processo de cumprimento da pena de mulheres detentas e que mundos possíveis se estabelecem a partir da relação entre suas memórias de recepção desse conteúdo midiático nesse ambiente de novas sociabilidades." (JOHN, 2014, p. 25)

Adentrar a um universo empírico é sempre um grande desafio, mas também uma experiência única. Embora o ambiente prisional não representasse uma novidade como campo de pesquisa, cada momento, cada etapa da pesquisa, cada observação e anotação e, sobretudo, cada entrevista realizada se constituíram num momento singular e desafiador. Exigiram a necessidade constante da auto avaliação, do exercício ininterrupto da reflexividade, como recomenda Galindo Cáceres (1997). Na perspectiva do autor, o

\footnotetext{
${ }^{1}$ Referência ao evento intitulado Cátedra Jesús Martín-Barbero: De los medios a las mediaciones - 30 anos!, realizado nos dias 30 de novembro e 1ำ de dezembro de 2017 no Programa de Pós-Graduação em Comunicação e Informação da Universidade Federal do Rio Grande do Sul, organizado pela profa. Dra. Nilda Jacks.

2 Para a realização do estudo, foram entrevistadas oito mulheres de diferentes faixas etárias, regimes e tempo de cumprimento de pena. O estudo foi realizado com mulheres detentas do Presídio Regional de Itajaí, cidade localizada no chamado "Vale Europeu", no litoral norte catarinense.
} 
investigador é sempre o sujeito central de qualquer estudo. "Pesquisar é a busca, em última instância, de conhecer a si mesmo, de promover o encontro entre o interior e o exterior, entre o mundo de quem pesquisa e o que é pesquisado, entre os vários mundos possíveis que caracterizam cada cenário, cada objeto, cada fazer científico." (JOHN, 2014, p. 55).

Como toda pesquisa é também o resultado de escolhas, de recortes que se circunscrevem no interior das problemáticas que instigam o sujeito que investiga, também os caminhos para a realização do estudo passam pelas escolhas e tomadas de decisão do pesquisador. Nesse contexto, a pesquisa citada teve como fio condutor a Metodologia de los mundos posibles, proposta por Galindo Cáceres (1997), porém articulada pela perspectiva das mediações de Martín-Barbero e do modo como o campo foi determinante para o estabelecimento do quanto essa perspectiva se fazia fundamental para compreender a relação das participantes com a narrativa da telenovela, especialmente, com suas marcas melodramáticas. Utilizando-se da metáfora de Galindo Cáceres de que a metodologia de qualquer pesquisa é o "itinerário de viagem" de todo pesquisador, é possível dizer então que o caminho é o dos mundos posibles mas que o "guia de viagem" são as mediações "barberianas". Durante a realização da tese, costumava sempre fazer uma brincadeira sobre meu "caminho de iluminação" e dizer que, para ser doutora, foi necessário dedicar minha vida não a um, mas a dois "Jesús", e somava isso à coincidência de eu ter nascido em 25 de dezembro.

A perspectiva de Galindo Cáceres (1997) tem como um de seus aspectos centrais “[...] o entendimento de que o teórico e o empírico coadunam-se, ou seja, que a pesquisa se dá no âmbito da cultura onde o sujeito que pesquisa interfere, transforma o mundo que irá tentar compreender bem como será afetado e transformado por ele." (JOHN, 2014, p. 56). Significa dizer que não apenas o pesquisa interfere, modifica o espaço onde realiza seus estudos como também será afetado, modificado por ele. Ou seja, “[...] a metodologia, entendida pelo autor como o caminho a ser trilhado, não segue fora da vida, ao contrário, se faz, se constrói em seu interior." (JOHN, 2014, p. 56).

Outro aspecto central na proposição do autor é a necessidade de se evitarem as "certezas definitivas" ou as "verdades totalizadoras". A perspectiva é de que a pesquisa, e seus resultados, sejam sempre um mundo possível num universo de vários outros mundos possíveis e que isso não invalida o estudo, não o torna menos científico, ao contrário. Possibilita ao pesquisador estar livre para mudar de direção conforme seu contato com o campo e com os sujeitos assim o determine. 0 desenvolvimento da tese seguiu um percurso 
em que foi necessário, inclusive, mudar a problemática, rever o questionamento que até então norteava o estudo. Ao iniciar o contato com o campo de pesquisa:

[...] a pergunta centrava-se muito mais nas questões das relações de gênero e muito menos no próprio objeto que se pretendia compreender - a relação detentas-telenovela. 0 contato longo e progressivo com o campo foi demonstrando que as questões de gênero não eram menores nem menos importantes do que o imaginado, mas havia outros aspectos mais contundentes na relação das detentas com a telenovela, inclusive em suas próprias narrativas sobre essa relação, que mereciam ser colocados no centro da problemática, qual seja, a memória da recepção em sua relação com a vida antes do ingresso na prisão, como projeção de lembranças e de retorno ao ambiente familiar mas também como projeção dos mundos possíveis para além das grades. (JOHN, 2014, p. 57).

Nesse primeiro momento, a pesquisa partia da perspectiva e do modelo das mediações proposto por Martín-Barbero (2003) e, no andamento do campo, foi se configurando cada vez mais em direção à perspectiva dos "mundos possíveis" de Galindo Cáceres (1997). “As mediações obviamente estão presentes, mas não se constituíram no fio condutor da análise e reflexão realizadas, num efetivo aporte e/ou modelo metodológico, ainda que jamais tenham se desconectado da realização da pesquisa." (JOHN, 2014, p. 57). De certo modo, aproveitando a brincadeira do início deste texto, foi o Jesús mexicano quem me conduziu, me mostrou o caminho, e o Jesús hispano colombiano quem iluminou o trajeto, quem possibilitou compreender o locus investigado e as produções de sentido das mulheres detentas com relação à telenovela.

Então, somente para que fiquei claro, o mapa das mediações não foi um "modelo" estruturante, um protocolo da pesquisa, o que não significa que ele não tenha estado lá, durante cada etapa da pesquisa. E isso não se trata de uma "recusa" ao modelo, mas de, seguindo a proposição da metodologia de los mundos posibles, permitir que a realização do campo, que o empírico demonstrassem os "câmbios" necessários. Não se trata de dizer que a proposição de Galindo Cáceres rejeita os modelos. 0 autor propõe, no entanto, que mesmo partindo de modelo o pesquisador nunca perca de vista o fato de "[...] os modelos não dão conta da complexidade da vida, do cotidiano, da cultura, sempre em franca transformação." (JOHN, 2014, p. 58). Assim, “[...] os resultados vão se apresentando como mundos possíveis que devem ser postos em diálogo com outros mundos, por exemplo, com os resultados de outras pesquisas sobre o mesmo tema, cenário ou contexto investigado." (JOHN, 2014, p. $57)$. 
Ocorreu, então, seguindo essa perspectiva, a mudança de trajetória na realização da tese, qual seja, em vez de seguir o modelo das mediações de Martín-Barbero (2003), optei por realizar a discussão

[...] somente [das] [...] mediações que pudessem ser identificadas no contexto estudado e pensá-las dentro da perspectiva dos mundos possíveis que se apresentam nas narrativas de mulheres encarceradas na e sobre a prisão a partir de sua relação com a telenovela e das memórias ligadas a esse gênero melodramático. (JOHN, 2014, p. 58, grifo da autora).

Nesse contexto, evidencio a interrelação das mediações da socialidade, institucionalidade e ritualidade e, acima de tudo, a necessidade de voltar ao primeiro mapa do autor e encontrar numa espécie de nova "cotidianidade familiar" o caminho para compreender os usos e sentidos atribuídos à telenovela por essas mulheres durante o cumprimento de sua pena.

A pesquisa é, como nas palavras de Galindo Cáceres, "um fragmento", uma busca de compreensão dos mundos possíveis que se estabelecem entre essas mulheres, sua nova rotina, memórias e novas formas de relacionarem-se com a telenovela. A seguir,apresento o "itinerário" teórico metodológico que conduziu a realização da pesquisa e inicio por um breve panorama da perspectiva dos mundos possíveis (na filosofia e ciências sociais) de modo a melhor contextualizar a metodologia de los mundos posibles (CÁCERES, 1997).

\section{Ponto de partida - os mundos possíveis}

A ideia de mundos possíveis mantém uma relação mais estreita com os domínios da Literatura e da Filosofia. Na perspectiva da Filosofia, mais especificamente no âmbito da lógica modal e da metafísica, considera-se como mundo possível uma situação contrafactual, ou seja, que não ocorreu, mas é perfeitamente cabível em termos lógicos, ou seja, poderia ter acontecido. No caso da Literatura, seu reconhecimento é mais fácil e, em larga medida, mais aceitável, pois o que constitui, justamente, o âmbito do fazer literário é a possibilidade de levar ao leitor mundos diversos que serão apreendidos por sua capacidade mental também de diversas formas e em múltiplos entendimentos. Entre leitor e texto, naturalmente não apenas o literário, se estabelecem conexões e interações ainda hoje difíceis de serem compreendidas. Como afirma Bruner (1997, p. 5), “Os linguistas literários e gerais sempre insistiram que nenhum texto, nenhuma história pode ser entendida em um único nível." Apoiando-se na perspectiva de Roman Jakobson, Bruner destaca que “[...] todo sentido é 
uma forma de tradução e que a tradução múltipla (polissemia) é mais a regra do que a exceção [...]". Porém, o autor enfatiza o quão pouco se conhece e se compreende, psicologicamente, dessa relação entre leitor e texto. Destacando a perspectiva da relação leitor-texto como um cenário de "mundos possíveis", Bruner (1997, p. 7) ressalta a posição de Paul Ricouer de que as histórias "são modelos para a redescrição do mundo". Entretanto, explica que "[...] a história não é por si mesma o modelo. Ela é, por assim dizer, uma instanciação dos modelos que carregamos em nossas próprias mentes”. (BRUNER, 1997, p. 7).

Deste modo, numa perspectiva semiótica, que também perpassa a trajetória de Martín-Barbero bem como a proposição de Galindo Cáceres (1997), os mundos possíveis da literatura e da relação leitor-texto e leitor-dentro-do-texto se dá justamente na correlação, confronto e, portanto, na interpretação e atribuição de sentido entre os mundos já existentes na mente do sujeito e os propiciados pelo texto. Entender a perspectiva dos mundos possíveis nesse processo semiótico permite ao pesquisador compreender (ou buscar compreender) melhor a complexidade do cenário e dos sujeitos da pesquisa, pois "Na medida em que a riqueza semiótica se associe a uma variedade de mundos conhecidos em lógicas de comparação e generalização, maior será a capacidade de enfrentar a configuração de um novo fragmento de mundo." (GALINDO CÁCERES, 1997, p. 28, tradução nossa).

Uma telenovela, embora seja outro tipo de texto, com conexões e interações mentais distintas, também estabelece conexões diversas com seus receptores. Já nesse âmbito, na projeção de pensar cognitivamente a interação sujeito-telenovela a partir da perspectiva leitor-texto da literatura se vislumbra um cenário de "mundos possíveis". Na pesquisa realizada, porém, a concepção de "mundos possíveis" está - ainda que em diálogo com a perspectiva das ciências cognitivas - circunscrita ao âmbito da Comunicação e seu diálogo mais estreito com as Ciências Sociais e a História, seguindo o percurso da metodologia de los mundos posiblesproposta por Galindo Cáceres (1997). Esta estabelece o diálogo com as ciências apontadas, mas propondo um "itinerário de viagem" para a pesquisa em Comunicação, notadamente para os estudos que envolvem os sujeitos, o âmbito da recepção dos conteúdos midiáticos, como a pesquisa realizada.

A metodologia dos "mundos possíveis" na perspectiva das Ciências Sociais e da História, um dos pontos de partida de Galindo Cáceres, não é algo corriqueiro ou plenamente aceito, ao contrário, é um campo de controvérsias, contestações e que suscita 
diversas reflexões. Como aponta Hawthorn (1995), nem nas Ciências Sociais nem na História tem-se "[...] visto com clareza o que se pode ganhar em desenvolvê-lo [os mundos possíveis]. A maioria dos historiadores e dos cientistas sociais, se levam algo em conta dos contrafactuais, o têm feito com nervosismo e em escritos marginais." (p. 6). Esses aspectos também são apontados por Galindo Cáceres (1997) quando de sua proposição para o cenário da Comunicação. Como aponta o autor, "A metodologia dos mundos possíveis se sustenta sobre vários pressupostos que implicam polêmica e reflexão." (GALINDO CÁCERES, 1997, p. 35, tradução nossa).

Proposições mais contundentes dos "mundos possíveis" nas áreas das Ciências Sociais e da História se deram entre 1970 e 1990, e um desses representantes é Geoffrey Hawthorn, com a publicação de Plausible words, em 1991, traduzida para o espanhol, em 1995³, com o título Mundos plausibles, mundos alternativos, ainda hoje sem tradução para o português (HAWTHORN, 1991; 1995). Sobre sua proposição, o autor afirma que quer “[...] respaldar os direitos do possível: argumentar que tomá-lo em conta é fazer algo mais que se dedicar a jogos de salão sobre o-que-poderia-ter-sido." (HAWTHORN, 1995, p. 15, tradução nossa).

Hawthorn discute a possibilidade e a validade das ideias contrafactuais para o estudo nas Ciências Sociais e na História, particularmente esta última. Constrói sua linha de argumentos a partir de exemplos plausíveis, de possibilidades contrafactuais como o que poderia ter ocorrido na história se Granada não tivesse saído derrotada em 1492. Reconstroi o desenvolvimento do conceito ao longo da história das assim chamadas Ciências Humanas e Sociais; sobre como a validade de se estudar os contrafactuais - os mundos possíveis - foi sendo refutada, vista como contrária à ideia de razão e de verdade. Utilizando a definição de Robert Musil em The man without qualities, Hawthorn (1995) propõe que "Se existe algo denominado sentido da realidade [...] então também tem que ter algo chamado sentido da possibilidade." (HAWTHORN, 1995, p. 6, tradução nossa).

Entre outros aspectos, destaca a importância do estudo, da análise das particularidades, que não devem se propor a generalizações mas que podem trazer significativas contribuições para a busca da compreensão da realidade histórica em sua articulação passado, presente, futuro. 0 que o autor propõe é "[...] reconhecer a importância de uma compreensão mais ampla, [...] porém a resistir a suposição comum nas ciências

\footnotetext{
${ }^{3}$ A obra foi traduzida por sua esposa Gloria Carnevali Hawthorn com a participação do autor e foi editada/impressa pela Cambridge University Press, de Cambrige, Reino Unido.
} 
sociais de que as narrativas gerais expõem suficientemente essa compreensão." (p. 52). Neste âmbito, os contrafactuais não são um afastamento da realidade ou da "verdade" mas uma outra (ou outras) possibilidade de compreendê-la.

[...] na explicação, as possibilidades aumentam ao mesmo passo que diminuem. [...] uma explicação sugere outras opções. Sob a explicação, as possibilidades aumentam. [...] Isto se deve ao fato de que a força de uma explicação gira em torno do contrafactual que implica. A implicação é que se tal e tal combinação de causas não estivessem presentes, ou que se tal e tal ação ou série de ações não tivessem sido levadas a cabo, as coisas teriam sido diferentes. Se não cremos nisso, então não deveríamos dar às causas e às ações em questão a importância que lhes estamos dando. (HAWTHORN, 1995, p. 19-20, tradução nossa).

Algumas dessa reflexões (e provocações) estão presentes na proposição de Galindo Cáceres. Pode-se dizer que a perspectiva de Hawthorn quanto ao contexto das explicações (e a impossibilidade do conhecimento) está em sintonia com as ideias de Galindo Cáceres quanto à importância do que ele denomina configuração. Hawthorn (1995) enfatiza o caráter mutável das explicações, reiterando que estas não são fixas e que não “[...] existe nada no mundo que nos diga que são. E não existe um bom argumento externo para impor um certo tipo [de explicação] [...]” (p. 20), o que passa pelas escolhas teóricas e, assim, constituem mundos possíveis.

A proposição de Galindo Cáceres (1997) congrega três aspectos: a configuração, a trajetória e a noção de forma de energia. A configuração, como eixo sincrônico na proposição do autor, pode ser entendida como o âmbito da própria cultura, daquilo que é móvel e paradoxalmente precisa ser transformado em fixo, como etapa do conhecimento. Para dar conta desse "aprisionamento" do que é móvel, algo que se faz pela linguagem (a escrita da tese ou deste artigo) faz-se necessário um eixo temporal ou histórico, chamado pelo autor de trajetória. Esta é “[...] o curso mesmo do possível configurável, quer dizer, a partir de um ponto se abrem várias alternativas e configurações paralelas possíveis, todas dentro da lógico do configurável. 0 movimento traz consigo a presença teórica dos mundos possíveis." (GALINDO CÁCERES, 1997, p. 38). A energia é o que articula os outros dois eixos, é o sujeito pesquisador, os sujeitos pesquisados, ou seja, a dinâmica da própria vida humana. Este eixo se faz indispensável uma vez que, como afirma o autor: 
Configurações e trajetórias são formas construídas nos limtes do tempo e do espaço, conforme se compreenda nessa encruzilhada serão entendidas as formas. E se são formas precisamos entender seu conteúdo. 0 sentido alcançado até hoje sugere como elementar o curso configuracional das formas de energia. A energia está dentro do todo o possível, o possível é a forma da energia. (GALINDO CÁCERES, 1997, p. 41, tradução nossa). ${ }^{4}$

Foi, portanto, na conjunção desses três eixos que “[...] se buscou compreender a relação que se estabelece entre as mulheres detentas e a telenovela no ambiente prisional, quais mediações atravessam esses mundos possíveis e quais mundos possíveis se constroem nesse ambiente." (JOHN, 2014, p. 65).

\section{0 encontro com as mediações}

Embora a tese tenha se desenvolvido em termos metodológicos a partir da proposição de Galindo Cáceres (1997), ela foi norteada desde o início e ao longo de todo o processo pela perspectiva teórica de Martín-Barbero (2003) no que se refere ao contexto das mediações, aos "usos sociais dos meios". A pesquisa se norteou, portanto, pela perspectiva de que a relação entre os sujeitos (neste caso as detentas) e os conteúdos midiáticos (a telenovela) não é unilateral e sim multidimensional. Neste sentido, considero importante retomar, ainda que brevemente, a discussão sobre mediações. Conforme explica Jacks (1997, p. 5), a proposição de Martín-Barbero refere-se, sobretudo, a “[...] localizar os problemas de comunicação em outro campo, o dos processos sócio-culturais". Ou seja, "indica a entrada ao campo pelo estudo das instituições, organizações e sujeitos, pelas diversas temporalidades sociais e multiplicidade de matrizes culturais." (p. 5). Como define o próprio autor:

É indubitável que o estudo de recepção, no sentido em que estamos discutindo, quer resgatar a vida, a iniciativa, a criatividade dos sujeitos; quer resgatar a complexidade da vida cotidiana, como espaço de produção de sentido; quer resgatar o caráter lúdico da relação com os meios; quer romper com aquele racionalismo que pensa a relação com os meios somente em termos de conhecimento ou de desconhecimento, em termos ideológicos; quer resgatar, além do caráter lúdico, o caráter libidinal, desejoso, da relação com os meios. (MARTíN-BARBERO, 2003, p. 54).

\footnotetext{
${ }^{4}$ Original: “Configuraciones y trayectorias son formas construidas en los límites del tiempo y del espacio, según se entienda en la encrucijada se entenderán las formas. Y si son formas necesitamos entender su contenido. El sentido alcanzado hasta hoy sugiere como elemental el curso configurativo de las formas de la energía. La energía está dentro de todo lo posible, lo posible es forma de la energía." (GALINDO CÁCERES, 1997, p. 41).
} 
A tese realizada é um estudo de recepção, mas é importante relembrar que recepção e mediação não devem ser tomadas como sinônimo. "Para Martín-Barbero, as mediações estão entre a Comunicação (os processos de produção, conteúdos, interesses, questões ideológicas, entre tantos outros aspectos) e a cultura, em seu sentido antropológico mais amplo, como o espaço e o conjunto das práticas que permeiam o processo da constituição dos sujeitos." (JOHN, 2014, p. 66). Significa dizer, portanto, que:

[...] entre a comunicação (também no sentido amplo, mas, sobretudo aquela institucionalizada, que passa pela difusão dos meios) e a recepção desses conteúdos há o lugar onde a cultura se manifesta, permeada por todas as ritualidades, as instituições, as crenças, os valores, os comportamentose os contextos culturais onde os sujeitos estão inseridos. (JOHN, 2014, p. 66).

Na primeira edição de De lós medios a las mediaciones, Martín-Barbero (2003) propôs três grandes lugares de mediações: a cotidianidade familiar, a temporalidade social e a competência cultural. "Esses três lugares alteram, interferem, participam do processo de recepção e atribuição de sentidos por parte dos sujeitos aos conteúdos midiáticos a que têm acesso e, naturalmente, serão mediados por eles." (JOHN, 2014, p. 67). Ao longo das décadas seguintes, o autor revisou e propôs mudanças em suas mediações. Já na Introdução à quinta edição da obra em espanhol (MARTÍN-BARBERO, 1998), o autor propõe uma nova teia de mediações, quando passa a falar em "mediações comunicativas da cultura". A proposição pode ser melhor visualizada na figura disposta a seguir:

Figura 1 - Mapa das mediações

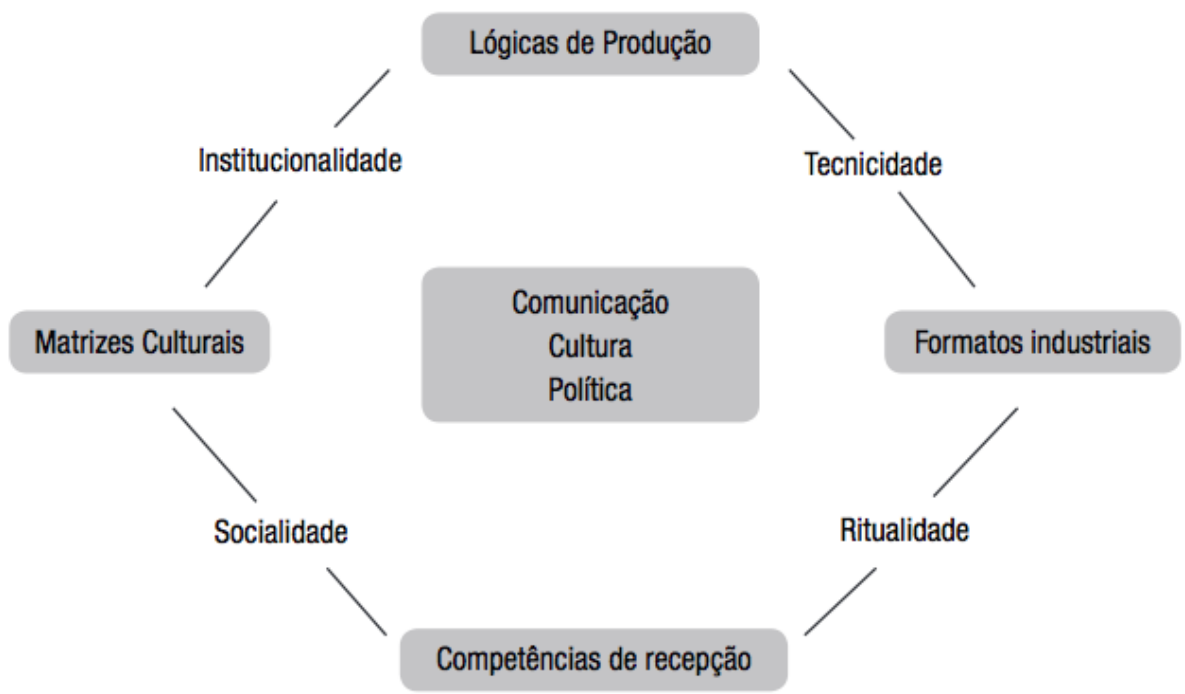

Fonte: Adaptado de Martín-Barbero (2011) por John (2014). 
0 modelo evidencia que entre os eixos propostos estão agora quatro mediações: socialidade, ritualidade, tecnicidade ${ }^{5}$ e institucionalidade ${ }^{6}$. Diferentes regimes de institucionalidade medeiam as relações entre as Matrizes Culturais (MC) e as Lógicas de Produção (LP), ao passo que as relações entre as MC e as Competências de Recepção (CR) são mediadas pelas diversas formas de socialidade. Já as Lógicas de Produção (LP) e os Formatos Industriais (FI) são mediados pelas tecnicidades e, por fim, FI e CR são mediadas por diferentes níveis e formas de ritualidade (MARTÍN-BARBERO, 2003).

Na pesquisa realizada,-não utilizei o modelo proposto por Martín-Barbero. Deste modo, embora possa afirmar que os resultados do campo apontam em algum momento para cada uma das quatro mediações sugeridas no modelo apontado na figura 1, a análise, articulada a partir de los mundos posibles, de Galindo Cáceres (1997), abordou principalmente duas mediações: a socialidade e a institucionalidade, “[...] as quais se mostraram mais contundentes no cenário analisado, dentro das possibilidades de realização da pesquisa." (JOHN, 2014, p. 68).

Essas duas mediações podem ser percebidas como articuladoras do duplo movimento entre as MC e as CR e destas com as LP, relação esta mediada, como destaca Martín-Barbero (2003, p. 17), “[...] pelos movimentos de socialidade, ou sociabilidade, e pelas mudanças na institucionalidade." No que se refere à mediação da institucionalidade, foi possível observar a interferência das regras da prisão no ver telenovela, ou seja, as “[...] mudanças não apenas na forma de acesso ao meio, mas também nas novas práticas institucionais impostas pelo próprio ambiente prisional, como por exemplo, o estabelecimento de horários para ver TV e a punição pelo mau comportamento com a retirada do aparelho na hora da exibição da novela." (JOHN, 2014, p. 69). ${ }^{7}$ Entretanto, a pesquisa também evidenciou as "brechas", ou seja, as formas de resistência.

É importante frisar, neste sentido, que no ambiente prisional se evidencia uma correlação entre as mediações da institucionalidade e da socialidade. Nesse ambiente

\footnotetext{
5 “É a mediação que se localiza entre os Formatos Industriais e as Lógicas de Produção e remete à construção de novas práticas através das diferentes linguagens dos meios, de modo simplificado por ser entendida como a interferência que a tecnologia exerce sobre a cultura." (JOHN, 2014, p. .68).

${ }^{6}$ Está entre as Lógicas de Produção e as Matrizes Culturais, relaciona de forma mais próxima a produção e a recepção. "Vista a partir da institucionalidade, a comunicação se converte em questão de meios, isto é, de produção de discursos públicos cuja hegemonia se encontra hoje paradoxalmente do lado dos interesses privados." (MARTÍN-BARBERO, 2003, p. 18).

${ }^{7}$ Esse aspecto foi destacado pelo diretor da Unidade Prisional já na primeira conversa para solicitar autorização para realizar a pesquisa. Na ocasião (setembro de 2012) a novela exibida era Avenida Brasil (AVENIDA BRASIL, 2012) e ele afirmou categoricamente que elas sabiam que se não se comportassem, "ficariam sem ver a Carminha".
} 
[...] é a socialidade (tanto as memórias e experiências anteriores quanto e, sobretudo, as novas práticas a que são submetidas, novas formas de convívio e novos laços de pertencimento) fator determinante no modo como se relacionam com a telenovela e esta é importante e significativa no modo como desenvolvem essas novas práticas e como são "institucionalizadas." (JOHN, 2014, p. 70).

A pesquisa evidencia, portanto, a socialidade como a principal mediação entre as detentas e a telenovela, bem como a telenovela como principal mediadora de suas práticas de socialidadee sociabilidade e reforça, como dito, a importância teórico epistemológica de Martín-Barbero para a realização do itinerário da pesquisa aqui relatada. A centralidade dessa mediação não é, porém, exclusividade desta pesquisa. A importância dessa mediação no sentido amplo da proposição do autor pode ser melhor compreendida a partir da definição do próprio Martín-Barbero:

A socialidade, gerada na trama das relações cotidianas que tecem os homens [e as mulheres] ao juntarem-se, é por sua vez lugar de ancoragem da práxis comunicativa e resulta dos modos e usos coletivos de comunicação, isto é, de interpelação/constituição dos atores sociais e de suas relações (hegemonia/contra-hegemonia) com o poder. Nesse processo, as MC ativam e moldam os habitus que conformam as diversas Competências de Recepção. (MARTíN-BARBERO, 2003, p. 17, grifo do autor).

Além da socialidade, outra mediação articulada e tensionada a partir do trabalho de campo foi a da ritualidade. "Simplificadamente, esta pode ser definida como os usos e as formas como os sujeitos se relacionam com os conteúdos midiáticos." (JOHN, 2014, p. 70). Como afirma Martín-Barbero (2003, p. 19-20, grifo nosso):

A mediação das ritualidades remete-nos ao nexo simbólico que sustenta toda comunicação: à sua ancoragem na memória, aos seus ritmos e formas, seus cenários de interação e repetição. Em sua relação com os FI (discursos, gêneros, programas e grades ou palimpsestos), as ritualidades constituem gramáticas da ação - do olhar, do escutar, do ler - que regulam a interação entre os espaços e tempos da vida cotidiana e os espaços e tempos que conformam os meios. [...] Vistas a partir das CR, as ritualidades remetem, de um lado, aos diferentes usos sociais dos meios [...] De outro lado, as ritualidades remetem às múltiplas trajetórias de leitura ligadas às condições sociais do gosto, marcadas por níveis e qualidade de educação, por posses e saberes constituídos na memória étnica, de classe ou de gênero, e por hábitos familiares de convivência com a cultura letrada, oral ou audiovisual, que carregam a experiência do ver sobre a do ler e viceversa.

\footnotetext{
${ }^{8}$ Esta na perspectiva de Goffman (1999) e sua definição de instituições totais.

9 Entendida na perspectiva de "ressocialização", os processos sociais fortemente atravessados pela institucionalidade e institucionalização dessas mulheres (JOHN, 2014).
} 
É importante frisar, porém, que a ritualidade não foi observada no sentido de acompanhar a assistência da telenovela com as detentas, aspecto que embora fosse intencionado, não pode se concretizar devido às normas de segurança da Unidade Prisional. Essa mediação pode ser vislumbrada, porém, “[...] nas próprias falas das entrevistadas e, deste modo, foram elencados aspectos da ritualidadea partir de seus relatos bem como da observação de seu cotidiano nos horários e espaços permitidos." (JOHN, 2014, p. 71, grifo da autora).

Na pesquisa realizada, não se buscou a efetiva aplicação do modelo das mediações. Esse foi colocado em tensão e em estado de potência na proposição de se pensar a relação telenovela-detenta-memória-mundos da prisão e fora dela, na perspectiva da metodologia de los mundos posibles de Galindo Cáceres (1997), que se apresenta a seguir.

\section{A metodologia de los mundos posibles como fio condutor}

Realizar uma pesquisa na perspectiva de los mundos posibles envolve, segundo Galindo Cáceres (1997), três grande instâncias teórico metodológicas: a exploração, a descrição e a significação, e a cada uma delas corresponde uma técnica e/ou procedimento a ser adotado pelo pesquisador para melhor alcançá-la. Na etapa da exploração, o autor recomenda como principal instrumento o diário de campo. Esse instrumento foi utilizado durante todo o processo de realização da pesquisa, não apenas da observação inicial (e das vivências anteriores com a Unidade prisional). 0 diário de campo sintoniza-se diretamente com a etapa seguinte e com a proposição de procedimento que o articula,- a etnografia,método central para a etapa da descrição. Como aponta Galindo Cáceres (1997, p. 79, tradução nossa):

No momento da descrição da configuração objetiva [o pesquisador] se coloca como o centro da ação. Trata-se de elaborar e detalhar mapas do mundo objetivo em todas as dimensões possíveis. A aproximação ao exterior a partir do interior tem clareza e precisão. Os instrumentos básicos dessas tarefas são a etnografia e a estatística, componentes elementares do trabalho configurador ${ }^{10}$.

A principal recomendação (e lição) da perspectiva de los mundos posibles, especialmente do uso da etnografia como parte dos procedimentos, que norteou toda a

\footnotetext{
${ }^{10}$ Original: "En el momento de descripción de la configuración objetiva se coloca en el centro de la acción. Se trata de elaborar y detallar mapas del mundo objetivo en todas las dimensiones posibles. El acercamiento al exterior desde el interior tiene claridad y precisión. Los instrumentos básicos de estas tareas son la etnografía y la estadística, componentes elementares del trabajo configurador." (GALINDO CÁCERES, 1997, p. 79).
} 
realização da tese, "[...] é a consciência de que a subjetividade faz parte do processo, tanto por parte do pesquisador quanto dos sujeitos participantes." (JOHN, 2014, p. 72). Esta se faz presente em todas as etapas da pesquisa, porém, é na terceira e última etapa da proposição do autor em que ela se faz mais presente, daí a importância de o pesquisador estar em permanente processo de reflexividade quanto a esse aspecto. É na etapa da significação, ou seja, na escritura da tese (nesse caso), o momento em que a subjetividade mais se apresenta, mais se impõe como desafio.

\begin{abstract}
O momento da signficação é mais complexo e o mais intenso porque se retorna ao mundo interior com uma densidade de contato com o exterior muito profunda. Aquí o qualitativo adquire todo o seu peso, a linguagem é o principal instrumento e os limites são os bloqueios à imaginação e à criatividade. É o ponto da síntese, o ato configurador por excelência, o lugar da teorização da comunicação ${ }^{11}$. (GALINDO CÁCERES, 1997, p. 79, tradução nossa).
\end{abstract}

Foi justamente para o processo da significação, ou seja, da análise do campo e a escrita da tese em que os mundos posibles e as mediações mais se articularam. Foi, portanto, o respaldo teórico epistemológico das mediações que norteou a "vigilância" de minha conduta como pesquisadora.

Todas a pesquisa foi desenvolvida a partir das "vozes" das participantes, sendo que, para esse processo, foi utilizada a história oral. Essa foi articulada, a partir de Galindo Cáceres (1997), pela história de vida. Essa técnica também reafirma o princípio da subjetividade que opera durante toda a realização da pesquisa, aspecto que, como dito, exige o permanente exercício de reflexividade por parte do pesquisador, uma vez que a história de vida é, como afirma o autor, um profundo e complexo exercício de conhecer a si mesmo e de alteridade. "El contacto con la intimidad del otro es una prueba para la propia intimidad. De todas las posibles experiencias que un individuo puede tener la más compleja es la del encuentro con un semejante." (GALINDO CÁCERES, 1997, p. 125).

Na pesquisa realizada, a opção foi pela história de vida, adotada como técnica dentro da perspectiva maior da história oral. "Nessas entrevistas, buscam-se as singularidades das trajetórias pessoais e da visão de mundo de cada sujeito." (JOHN, 2014, p. 77). Ou seja, a trajetória de vida de cada uma das detentas, o que inclui seu cotidiano na prisão e os seus próprios "mundos possíveis" projetados para quando saírem da prisão. A história de vida é,

\footnotetext{
11 Original: "El momento de significación es el más complejo y el más intenso porque se regresa al mundo interior con una densidad de contacto con el exterior muy profunda. Aquí lo cualitativo adquiere todo su peso, el lenguaje es lo más instrumental y los límites son los bloques a la imaginación y a la creatividad. Es el punto de la síntesis, el acto configurador por excelencia, el lugar de la teorización de la comunicación.” (GALINDO CÁCERES, 1997, p. 79).
} 
para Galindo Cáceres (1997), uma técnica fundamental, uma vez que

\begin{abstract}
Lo individual puede ser considerado como una proyección de lo general en lo particular, de este modo las historias particulares, los discursos desde lo particular, son formaciones que implican y expresan a la sociedad y la cultura más generales. Con tal visión la historia de vida no sólo es importante sino central en la aproximación a lo sociocultural. (GALINDO CÁCERES, 1997, p. 125).
\end{abstract}

Optar pela história de vida é também resultado da correlação entre as proposições de Galindo Cáceres (1997) e Martín-Barbero (2003). Ambos evidenciam a importância de se valorizar os contextos e as trajetórias onde se inserem os sujeitos e a relação destes com as narrativas midiáticas, no caso da tese significativa, portanto, a valorização das trajetórias e do cotidiano das mulheres detentas. Ainda no que se refere à opção pela história de vida como técnica fundamental da pesquisa realizada, é importante lembrar que o objeto norteador do estudo foi a telenovela, e esta também é uma narrativa que, em alguma medida, estabelece relações de mimese com a "vida real". Articulada à noção maior de mundos possíveis, é possível afirmar que "[...] cada uma das histórias de vida é também, em alguma medida, um dos mundos possíveis, tanto em termos de relação campo-teoria, como se espera de qualquer pesquisa, quanto para além dela, para a definição do que se entende por vida vivida." (JOHN, 2014, p. 79).

\title{
50 retorno às mediações - evidências do trabalho de campo
}

As mediações de Martín-Barbero não constituíram, como dito, o modelo metodológico da pesquisa realizada. Ao contrário, foi o contato com o campo, realizado a partir da proposição da metodologia de los mundos posibles, quem evidenciou as mediações que mais efetivamente participavam do processo de produção de sentidos das mulheres detentas em relação à telenovela. Significa dizer que Martín-Barbero (2003) foi fundamental para a compreensão dos significados da telenovela e do melodrama para essas mulheres. Na perspectiva deste texto, de apresentar o itinerário teórico metodológico da pesquisa realizada, finalizo trazendo a mediação fundamental que me possibilitou tensionar os mundos possíveis que articulam o cotidiano e as trajetórias de vida dessas mulheres com a telenovela e suas memórias. Trata-se da mediação da socialidade (e, no caso da prisão, sua indissocialidade da mediação da institucionalidade) e da necessidade de voltar à mediação do "mapa noturno", qual seja, a cotidianidade familiar, o que reforça, como já apontado por 
Galindo Cáceres, que os modelos não são fixos, já que a cultura e a vida também não o são. Finalizo, portanto, trazendo brevemente as percepções articuladas por esse mediação.

Na prisão, entre os principais aspectos que medeiam a relação das detentas com a telenovela está a questão do horário. Sobretudo as que têm alguma ocupação (trabalho na oficina de costura ou na cozinha, por exemplo) atribuem à TV, no horário noturno, uma forma de lazer, de descanso e, nesse processo, de projeção para suas vidas fora da prisão, seja pelo acionamento das memórias que envolvem suas famílias, seja pelos planos para quando saírem da prisão, mas principalmente pela perspectiva de, ao acompanharem as trajetórias das personagens de sua preferência, conseguirem se ver "fora da prisão". Aspecto esse que também perpassa o cotidiano daquelas que não trabalham. Ao usar expressões como "passar o tempo", "distrair", "ocupar a mente", nos termos usados por elas ao se referirem à telenovela, evidencia-se o encontro com esse "outro lugar", mundos que são absolutamente plausíveis dada a conexão que elas estabelecem entre novela e "vida real". Mas tudoisso é fortemente mediado pelas regras do local onde se encontram, portanto, esse relação com a telenovela só é possível porque:elas têm a autorização da administração da unidade para ter o aparelho de TV; se "comportam" para não perderem esse privilégio e porque elas negociam entre si, ao compartilharem um único espaço, tanto a posição em que a TV vai ficar na cela, quanto o volume, o horário e os canais que serão assistidos.

Esse conjunto de aspectos, tanto narrados por elas quanto observados em seus locais de "moradia", evidencia um imbricamento entre as mediações da socialidade e da institucionalidade e até mesmo da ritualidade, pois até a ordem para quem vai tomar banho primeiro, no caso daquelas que trabalham e seguem juntas para a cela, quem escolhe o canal. Tudo isso, segundo suas narrativas, é negociado de forma tranquila porque existe o consenso, ao menos no período noturno, de que a novela é "a melhor coisa pra assistir".

Ainda quanto a esse aspecto, pode-se dizer que as lógicas de socialidade a que estão submetidas (por exemplo, dividir a cela) e da própria institucionalidade (a oferta da programação mas também as imposições da própria unidade prisional) promovem o hábito de ver novela até mesmo entre aquelas que dizem ter começado a ter contato com esse conteúdo somente na prisão. Não apenas uma questão de ocupação do tempo, mas da própria falta de acesso a outros bens culturais. E há também outro aspecto da mediação da institucionalidade, qual seja, a oferta de bens midiáticos na prisão. A entrada de livros, jornais e revistas é proibida na unidade e também não há uma biblioteca ou algo similar onde elas possam promover a prática da leitura. Os únicos bens midiáticos a que têm acesso 
são, portanto, o rádio e a TV, sendo que mesmo estes terão de ser negociados, tanto em termos "oficiais" quanto entre elas próprias.

A mediação da socialidade aponta, ao menos entre um dos grupos participantes da pesquisa, o grupo das que trabalham na cozinha da unidade, um retorno à primeira mediação sugerida por Martín-Barbero (2003) - a da cotidianidade familiar. A importância dessa mediação está destacada em vários estudos de recepção de telenovela. Num dos estudos mais aprofundados sobre a relação família e telenovela já realizado no Brasil, Lopes, Borelli e Resende (2002) enfatizam a importância dessa instituição - a família - e suas lógicas cotidianas no atravessamento com as narrativas da telenovela. Entre os vários aspectos problematizados e destacados pelas autoras, é importante a constatação de que “[...] a família não é só o modelo de assistência da telenovela, como a telenovela é um texto melodramático televisivo para ser lido e fruído de forma coletiva, especificamente em contato com outros, em grupo, em família." (LOPES; BORELLI; RESENDE, 2002, p. 141).

Foi possível observar no cotidiano das entrevistadas, no local onde trabalham, bem como em suas narrativas, uma série de "rituais" relacionados à família. "Não se trata de dizer que elas formaram uma nova família, mas que isso foi se configurando em termos de atribuição/divisão de tarefas, estabelecimento de regras de convivência e uma afinidade que foi surgindo entre elas." (JOHN, 2014, p. 155). Inclusive de um atributo de hierarquias que entre elas não se refere à faixa etária, mas a quem é a "mais antiga" no trabalho na cozinha. A seu modo, esta "família" também estabelece suas regras de convivência.

Pode-se perceber, então, uma espécie de "cotidiano familiar" que medeia diretamente a relação com a telenovela. Entre vários outros aspectos de interferência da família no ver telenovela, Lopes, Borelli e Resende (2002) apontam a questão da própria "espacialidade familiar", onde entram aspectos, como por exemplo, "[...] os acordos físicos e emocionais pelos quais se estabelecem as fronteiras do mundo social da família e do mundo particular de cada membro." (p. 141). Ainda conforme as autoras, "A espacialidade familiar permite revelar não apenas os espaços domésticos de assistência da televisão, mas também os espaços de circulação da telenovela.". (p. 142, grifos das autoras).

No caso das "meninas da cozinha", esse espaço se amplia da cela para a cozinha. Em geral, era lá que o debate se fazia mais presente, inclusive quando interagiam com outros membros da instituição, como os e as agentes e, ocasionalmente, com a equipe administrativa. Esse aspecto esteve mais presente no período final de cada novela exibida ao longo do trabalho de campo, particularmente durante a reta final da telenovela Avenida 
Brasil, da Rede Globo, justamente quando teve início a pesquisa. O debate envolvendo os próprios funcionários da instituição se mostrou mais contundente. A "audiência" do folhetim foi tão importante nesse período que elas relatavam os gritos de empolgação que ouviam nos pavilhões, tanto masculino quanto feminino.

Um desses gritos levou à punição de um grupo de mulheres do qual uma das participantes da pesquisa fazia parte, e o castigo foi perder a exibição do último episódio da novela. Esse aspecto já havia sido apontado pelo diretor quando da primeira conversa para dar início à pesquisa. Então, qualquer tipo de desobediência às regras tinha como punição a retirada da TV da cela. E essa retirada ocorria em um horário determinado: exatamente quando se iniciava a novela de forma a agravar ainda mais o "suplício". Como se vê, a mediação institucional tem um peso importante no modo como assistem à novela (e qualquer outro conteúdo).

Outro aspecto que evidencia a mediação da institucionalidade é, como já dito, a questão do horário, tanto na perspectiva da instituição midiática, que define a grade de programação, quanto a da instituição prisional: ver a novela depende de adequar sua jornada ao ambiente. Ou seja, o horário quando terminam de trabalhar, a ordem de quem vai tomar banho, o horário em que se deve fazer silêncio (a partir das $22 \mathrm{~h}$ ), o horário de acordar. Aspecto esse que, em sintonia com a ideia de cotidianidade familiar, pensando especificamente o tempo em que permanecem em suas celas, remete à interferência da "temporalidade familiar", tal como apontado por Lopes, Borelli e Resende (2002). Segundo as autoras:

A programação temporal implica a regulação do tempo em termos de sequência, frequência, ritmo, duração e horário das atividades familiares. Ela se corporifica em rotinas diárias da família e de seus membros, e atende às exigências de organização da vida cotidiana, seja dentro de casa ou no mundo exterior. (LOPES; BORELLI; RESENDI, 2002, p. 142-143).

Ainda sobre a questão da temporalidade familiar, as autoras destacam que há, “[...] por um lado, a temporalidade da televisão que se impõe e conforma o cotidiano da família. Porém, essa temporalidade não é exclusiva, pois necessariamente vai ter de ser negociada com a temporalidade interna, específica da família." (LOPES; BORELLI; RESENDI, 2002, p. 143). No caso das entrevistadas que trabalham na cozinha ou outra participante que trabalhava na oficina de costura, pode-se dizer que o fato de só terem tempo à noite para ver televisão constrói um cenário propício para a eleição da telenovela como principal 
conteúdo. Por outro lado, elas mesmas afirmam que poderiam ver outras emissoras ou outros canais de TV e não o fazem porque "preferem as novelas da Globo".

Esta breve apresentação de uma das mediações mais importantes que percebi na relação das mulheres detentas com a narrativa e as memórias da telenovela reforça o quanto a proposição de Martín-Barbero foi fundamental para a compreensão de como essas mulheres co-relacionam suas trajetórias e memórias aos enredos da "novela das nove". A partir das ritualidades expressas em suas narrativas e dos regimes de socialidade e institucionalidade em que ver a telenovela se articula na prisão, foi possível compreender como o melodrama, ainda presente nessas tramas, se imbrica nos enredos melodramáticos de suas próprias histórias, configurando "futuros contingentes" dos mundos possíveis que elas projetam para quando saírem da prisão.

O percurso empreendido, que partiu das mediações "barberianas" para então perceber a necessidade da mudança de rumo, encontrando na metodologia de los mundos posibleso o "itinerário da viagem" salutar para o desenvolvimento da tese, reforça a importância que De los medios a las mediaciones desempenha não apenas em minha trajetória como pesquisadora, em minha busca de compreender a relação entre as narrativas midiáticas e o cotidiano deficitário da prisão, mas, sobretudo, a importância do autor para compreender aspectos profundos da América Latina, das culturas e camadas populares e daquilo que sugeri, a partir dos autores e dos resultados da pesquisa, de uma memória do melodrama como fundadora do inconsciente coletivo brasileiro. Como toda pesquisa, este relato, tal qual o fora a tese, segue inacabado, no sentido de ser ele próprio um mundo possível e ser sujeito ao contexto das mediações em que será lido.

\section{Referências}

AVENIDA BRASIL. Criador: João Emanuel Carneiro. Diretores: Amora Mautner; José Luiz Villamarim e Ricardo Waddington. Rio de Janeiro: Rede Globo, 2012. 179 episódios (3555min). 1080i (HDTV).

BRUNER, Jerome. Realidade mental, mundos possíveis. Porto Alegre: Artes Médicas, 1997.

GALINDO CÁCERES, Luis Jesús. Sabor a ti: metodologia cualitativa en investigación social. Xalapa: Universidad Veracruzana, 1997.

GOFFMAN, Erving. Manicômios, prisões e conventos. 5. ed. São Paulo: Perspectiva, 1999. 
HAWTHORN, Geoffrey. Mundos plausibles, mundos alternativos. Cambridge: Cambridge University Press, 1995.

HAWTHORN, Geoffrey. Plausible worlds. Cambridge: Cambridge University Press, 1991.

JACKS, Nilda. Audiência nativa: cultura regional em tempos de globalização. Intexto, Porto Alegre, v. 2, n. 2, p. 1-15, 1997.

JOHN, Valquiria Michela. Mundos possíveis e telenovela: memórias e narrativas melodramáticas de mulheres encarceradas. 2014. Tese (Doutorado em Comunicação e Informação) - Programa de Pós-Graduação em Comunicação e Informação, Universidade Federal do Rio Grande do Sul, Porto Alegre, 2014.

JOHN, Valquiria Michela. Palavras da salvação: as representações da leitura na prisão. 2004. Dissertação (Mestrado em Educação) - Programa de Pós-Graduação em Educação, Universidade Federal de Santa Catarina, Florianópolis, 2004.

LOPES, Maria Immacolata; BORELLI, Silvia Helena Simões; RESENDE, Vera da Rocha. Vivendo com a telenovela: mediações, recepção, teleficcionalidade. São Paulo: Summus, 2002.

MARTÍN-BARBERO, Jesús. De los medios a las mediaciones. Comunicación, cultura y hegemonia. 5. ed. Bogotá: Convenio Andrés Bello, 1998.

MARTÍN-BARBERO, Jesús. Dos meios às mediações: comunicação, cultura e hegemonia. 2. ed. Rio de Janeiro: UFRJ, 2003.

MARTÍN-BARBERO, Jesús. Dos meios às mediações. Comunicação, cultura e hegemonia. Rio de Janeiro: UFRJ, 2011.

\title{
From mediations to possible worlds: theoretical methodological trajectory of a reception study with imprisoned women
}

\begin{abstract}
This article presents the theoretical methodological trajectory of a research that articulates the proposition of the mediations of Jesús Martín-Barbero and how this made possible to understand the daily life of women in situation of confinement and how this one (re)configures from the mediation of the telenovela in this new environment of socialization. The Martín-Barbero map of the mediations was not the guiding thread of the study, which is guided by the perspective of the possible worlds of Galindo Cáceres, however, it's precisely at the meeting of these two theoretical methodological perspectives that we sought to understand how the telenovela mediates the daily life of women in prison. The text seeks to share the theoretical trajectory which Martín-Barbero's map of mediations' methodological
\end{abstract}


model doesn't show, but takes the central element found in the proposition of mediations to understand the telenovela in prison as an eminent instance of the possible worlds.

\section{Keywords}

Mediations. Possible worlds. Women in prison. Brazilian Telenovela. Reception research.

Recebido em 15/03/2018

Aceito em 13/05/2018 